\title{
Mixing Process of Binary Polymer Particles in Different Type of Mixers
}

\author{
S.M.Tasirin, S.K.Kamarudin \& A.M.A. Hweage \\ Department of Chemical and Process Engineering, Universiti Kebangsaan Malaysia \\ 43600 Bangi, Selangor, Malaysia \\ Tel: 60-3-8921-6422Ｅ-mail: ctie@vlsi.eng.ukm.my
}

\begin{abstract}
The main objective of this paper is to investigate the mixing process of free flowing polymers binary mixtures at different densities and colors in two different mixers, namely the bubbling fluidized bed and V-mixer. The mixing of solids was studied by analyzing the variation of the proportions of the marked particles with time and position in the bed or in the mixer. The variation of mixture composition based on the samples was incorporated into Lacey mixing index which describes the degree of mixing of the particles at particular time. The performance and the mixing behavior in these two mixers were also presented. Results showed that gas velocity and bed depth were important parameters influencing solids mixing in a bubbling fluidized bed. While the rotation speeds and filled up levels were proved as important parameters in influencing the solids mixing in V-mixer. From the results, complete mixings were attained at a bed depth of $17 \mathrm{~cm}$ and gas velocity of $1.38 \mathrm{Umf}$ in the fluidized bed and $40 \%$ filled up level and $40 \mathrm{rpm}$ in the V-mixer. From the energy consumption point of view, it was found that the fluidized bed mixer offers the most efficient and economical process compared to V-mixer.
\end{abstract}

Keywords: Particle, Mixer, Fluidized Bed, V-mixer

\section{Introduction}

A successful mixer must do at least two things; firstly, it must create differential velocities in the moving solid, which will produce mixing, Secondly, it must leave no dead, non-moving regions, as these regions cannot mix. Solids mixing are an important process in manufacturing many industrial products like pharmaceutical, chemical, petrochemical, foodstuffs, plastics, metallurgical, fertilizers, grain etc. but until now it is still one of the least well understood. Most of the solid mixing still based on the successful method for liquid mixing although it is proved unsuitable for the mixing of particulate solids. The fact that particles of different physical properties may tend to segregate has received considerable attention in the past few years but its implications have not been widely realized.

Thus the objectives of the study is to determine the optimum operating condition in order to obtain a final mixture of specified compositions of polymer A and B, namely, 3:1, respectively followed by investigating the mixing performance in V-mixer and fluidized bed. Finally, this study will determine the best type of mixer to be used in order to obtain the most efficient and economical mixing system.

\section{Theoretical Background}

For any manufacturing process that involves mixing of solid particles, the level of in homogeneity must be considered when determining the quality of the final product. It is even more difficult to obtain a homogeneous mixture when the particles are at different in size or in density (Stein et al. 2000).

Mixing index is directly proportional to the standard deviation: the smaller it is, the better the mixing will be. Considering number of samples, each containing particles, the estimated mixture composition value is given by Eq. (1) (Lacey 1954):

$\bar{y}=\frac{1}{N} \sum_{i=1}^{N} y_{i}$

Where the mixture composition, $y_{i}$ is $i$ th value of the proportion of one component in the samples.

We can use the standard deviation of the composition for the samples taken from the mixture as a measure of the quality of the mixture. Thus a low standard deviation indicates a narrow spread in composition of samples and therefore a good mixing is attained. The sample variance is given by Eq. (2). 


$$
S^{2}=\frac{1}{(N-1)} \sum_{i=1}^{N}\left(y_{i}-\bar{y}\right)
$$

The value of standard deviation, $S$ is calculated using equation (2) is only an estimation of the actual value of the standard deviation of the mixture, $\sigma$. The actual value of the standard deviation of a random binary mixture (in this case of a perfectly random system, lower limit), the variance $\sigma_{R}$ is as given by Eq. (3) (Lacey 1954; Lacey 1943; Fan et al. 1990):

${\sigma_{R}}^{2}=\left[\frac{P(1-P)}{n}\right]$

Due to that, the experimental values " $S^{2}$ " can be compared to $\sigma_{0}{ }^{2}$ and $\sigma_{R}{ }^{2}$ as defined as Lacey Index, $M$, for binary mixtures of identical particles as following:

$$
M=\frac{{\sigma_{0}}^{2}-\sigma^{2}}{{\sigma_{0}{ }^{2}-{\sigma_{R}}^{2}}^{2}}
$$

Where $\sigma_{2}$ is the variance of the mixture between fully random and completely segregated mixtures, $\sigma_{0}{ }^{2}=$ is upper limit (completely segregated) of mixture variance, $\sigma_{R}{ }^{2}=$ is lower limit (randomly mixed) of mixture variance and $\mathrm{M}$ is the Lacey mixing index. A Lacey mixing index of zero would re-present complete segregation and a value of unity would represent a completely random mixture. Particle values of this mixing index are found in the range of 0.75 to 1.0 (Rhodes 1998).

\section{Results and Discussion}

\subsection{Particle Characterization}

Two types of polymer particles considered in this study, namely polymer A (white) and B (black). Table 1 lists the physical properties of polymers used.

\subsection{Fluidized Bed}

Figure 1 shows the experimental set-up for fluidized bed. The system consists of a Perspex cylinder, $143 \mathrm{~mm}$ in diameter and $1000 \mathrm{~mm}$ length. A pressure probe connected to a water manometer measured the pressure drop across the bed. A transparent scale was attached on the bed wall to provide direct bed expansion measurement. The gas inlet system comprises of variable speed motor, a flow and gas distributor as proposed by Geldart (Geldart 1973). The total number of orifice was calculated to be 217 orifices. Compressed air at range from 0.4 to $0.6 \mathrm{MPa}$ a supplied from a central blower was used for fluidizing the air.

An experiment was started by charging a known weight of particles into the bed to give a predetermined settled bed depth as shown in Table 2. The bed depth used was chosen such that slugging won't occur in the bed. The critical bed depth, $H_{m s c}$ to onset slugging bed was calculated from equation (5).

$\left[\frac{H_{m s c}}{D}\right] \leq \frac{1.90}{\left(\rho_{P} \bar{d}_{p}\right)^{0.3}}$

In every case it was ensured that the polymer A (white) was at a fraction of $75 \%$ by volume (i.e. $71.3 \%$ by weight) while polymer B (black) $25 \%$ by volume (i.e $28.7 \%$ by weight) of the total weight fed into the column. Polymer A (white) was poured first into the bed, followed by the polymer B (black). This was to ensure that the two types of particle are fully segregated at the beginning of any experimental test. Compressed air at range from 0.4 to $0.6 \mathrm{MPa}$ was then supplied into the bed to fluidize the particles mixture. The air was supplied to give a gas velocity above the minimum fluidization velocity, Umf. The fluidization air was passed from a main compressor at ambient temperature and relative humidity $\pm 50 \%$. Side-sampling thief method was used for sampling.

\subsection{V-Mixer}

Figure 2 shows the schematic diagram of the V-mixer used in this study. The assembly is mounted on bearings and rotated by a variable speed electric motor. The identical cylindrical shells and access cover are produced in clear acrylic to permit viewing of the process. Each shell has an internal diameter of $8 \mathrm{~cm}$ and joined at an angle of $87^{\circ}$. The volume of the V-mixer is $1800 \mathrm{~cm} 3$. It was measured by measuring the volume of water necessary to fill up the whole containment. The access cover is secured by two thumb screws.

The experimental work was started by loading a certain weight of segregated feed materials consisting of a $75 \%$ by volume white polymer (A) and $25 \%$ by volume black polymer (B). The total weight of solids was varied to give different filled percentages in the V-mixer. In the beginning of each run, particles mixture was completely segregated. The V-mixer was turn rotated at a predetermined rotation speed for certain duration of time. Table 3 lists the 
parameters used in this case.

\section{Results and Discussion}

\subsection{Mixing Particles in Fluidized Bed Reactor}

Figure 3 shows an illustrative example of the mixing process for polymer particles in bed depth of $17 \mathrm{~cm}$. The superficial gas velocity was $1.38 \mathrm{Umf}$. The bed was first allowed to operate for $5 \mathrm{~s}$ in order to attain the steady state operation. The time was set to zero at this moment, after making sure that the black and white colored particles are completely segregated at $\mathrm{t}=0 \mathrm{~s}$. As mixing continous, this completely segregated state gradually gives way to one another in which the particles of different colors are partially mixed. A mixing equilibrium can be noted after about $6 \mathrm{~s}$ of mixing.

Figure 3 and Figures 4(a) and (b) show the bubbling fluidized bed, the bubble motion drives the solids motion. Bubbles carry particles upward in their wakes and drift. Continuously, this upward flow of solids due to bubbles was balanced by a downward flow which occurs at place where there are no bubbles. Particles move upward in the central part of the bed, and downwards beside the wall. This up-and-down movement is mean mechanism of vertical polymers (convective) mixing. Lateral mixing occurs mainly at the top of the bed where bubble burst; as illustrated in Figure 4 . Near the distributor, particles completed their old cycles and are carried away by bubbles to start new cycles.

Figure 5 shows images taken at different bed depths for each mixture. Resulting images reveal a completely homogenous comparison for mixing at $1.38 \mathrm{Umf}$ for $17 \mathrm{~cm}$ bed depth. Nevertheless, this mixture was spouted, as in Figure 6. Spouting is a condition which may occur when a single hole is used to admit the gas rather than a porous plate or multi-hole distributor (Chandnani \& Epstein 1986) or for group D and the larger group B particles. Nevertheless the phenomenon was observed only in the $17 \mathrm{~cm}$ bed, whilst no spouting was detected in the final mixture of $15 \mathrm{~cm}$ and 10 $\mathrm{cm}$ bed.

\subsection{Mixing in V-Mixer}

The photographs in Figure 7 was taken in order to investigate the mechanism of mixing, in which the mixer was stopped every certain time to examine the mixing quality. The figure shows the evolution of the surface composition for mixtures running at different time. It also shows that after $5 \mathrm{~min}$, a minimal degree of mixing has occurred. It should be noted that common practice in industry to mix particles takes for only a few minutes.

In general, it was observed that the mixing quality of polymer particles increases with increasing mixing time. This is due to the fact that the exchange rate of particles between the two end of the arms and reaching join of arms is particularly sensitive to mixing time with revolution speeds, also the dispersion the particles inside the V-mixer.

The mechanisms of mixing formation at different rotation speeds, i.e. 20, 40, and $60 \mathrm{rpm}$ are showed in Figure 8. From the photographs, it was observed that the mixture homogeneity at lower speed (i.e. $20 \mathrm{rpm}$ ) is less than the mixtures at higher rotation speeds (i.e. 40, and $60 \mathrm{rpm}$ ) at same conditions. Therefore, mixing index increases with an increasing rotation speeds. Results observed that a well mixed state was expected in each case, but it appeared that perfect mixing of polymer occurred at identical volume (i.e. $50 \%$ ) and optimum time for $40 \mathrm{rpm}$.

\subsection{Power Consumption}

Process optimization is important in order to produce the required product at a minimum energy or power consumption. From the study, it was proved that different operating parameters and different types of mixer gives the different optimal condition. Thus, to get homogenous mixtures at optimal conditions, the relation between the power consumption and the mixing index was established.

For mixing in V-mixer and Nauta-mixer, the ideal calculation indicated that the mixing index depends on the rotation speeds, as well as filled up levels, which indicate the amount of energy used.

The combination of these two parameters will indicate the optimum operation, namely to give the maximum value of mixing index, $\mathrm{M}$ at the lowest power consumed. Justification should be made to produce the largest amount of product but at the least amount of energy usage. In this case the energy consumed, E, is calculated by [1.047198*10-3.Rpm.t)/M] $(\mathrm{J} / \mathrm{kg})$.

The various mixing index can be compared on the basis of the specific energy consumption $(\mathrm{J} / \mathrm{kg})$. As seen in Figure 9 for mixing by V-mixer, the lowest overall energy losses (in $\mathrm{J} / \mathrm{kg}$ ) is at the mixing index value of 0.98 that is at the conditions of $40 \%$ filled up level with $20 \mathrm{rpm}$ and $40 \%$ filled up level with $40 \mathrm{rpm}$. The minimum energy consumption is at $20 \mathrm{rpm}$ rotation speed i.e. $\mathrm{E}=8.5$ and $9 \mathrm{~J} / \mathrm{kg}$ at 20 and $40 \mathrm{rpm}$, respectively. However, the minimum energy consumption to achieve as low as 0.99 mixing index value, i.e. to produce the best homogenous mixture is given from runs at 40 filled up level with $40 \mathrm{rpm} .40 \%$ filled up level with $40 \mathrm{rpm}$ is slightly homogenous than $40 \%$ filled up level with $20 \mathrm{rpm}$ but consumed more energy, (in $\mathrm{J} / \mathrm{kg}$ ).

For mixing by fluidized bed, the optimal mixing index depends on the gas flow rate, where the power consumption 
increases as gas flow rate increases. Figure 10 shows the results for specific energy consumption in mixing by fluidized bed. The results proved that fluidized bed consume very low energy that is in the range of 0.015 to $0.02 \mathrm{~J} / \mathrm{kg}$.

In order to calculate the realistic values of the specific energy consumption (in $\mathrm{J} / \mathrm{kg}$ ) it is necessary to make assumptions about the pressure drops across the distributor plate, as well as across the fluidized bed. Of course if the pressure drops are assumed to be the same for all the cases an alternative value can be calculated simply based on the gas flow rate and mixing time per mixing index and mass of solids quantity, K namely, (Q.pg.t)/(M.m) against the Lacey mixing index. In this case the optimum operation would be given by the condition at which the $\mathrm{K}$ value is minimum for a specified $\mathrm{M}$ value. From Figure 11, it is observed that the optimum operation for fluidized bed is at $17 \mathrm{~cm}$ bed depth with $1.38 \mathrm{Umf}$ because it offers the minimum value of $\mathrm{K}$, means minimum specific energy consumption, based on mixing index of 0.99 .

\subsection{Optimization}

From Figures 9 and 10, the optimum conditions for the V-mixer and fluidized bed mixer, respectively were compared and presented in Table 4. The mixing index of 0.99 can be regarded as an ideal mixing condition.

\section{Conclusion}

Two type of mixer are introduced in this study namely, the V-mixer and fluidized bed mixer. In conclusion, it was proved that fluidized bed is the most efficient and economical compared to V-mixer. The advantages of fluidized bed are: easy to handle and the complete mixing is attained in few seconds and consumed the lowest power losses.

\section{References}

Chandnani, P. P. and Epstein, N. (1986). Fluidization V, ed. K. Ostergaad and A. Sorensen, Engineering Foundation, New York, p. 233

Fan, L. T., Chen, Y. M. and Lai, F. S. (1990). Recent development in solids mixing. Powder Technology, 61, 255-287

Geldart, D. (1973). Type of gas fluidization, Powder Technology, 7, 285-292

Lacey, P. M. C. (1943). The mixing of solid particles, Transactions of the Institution of Chemical Engineers, 21, 53-59

Lacey, P. M. C. (1954). Developments in the theory of particulate mixing. Journal of Applied Chemistry, 4, 257-268.

Rhodes, M. J. (1998). Introduction to Particle technology, John Wiley, Chichester

Stein, M., Ding, Y. L., Seville, J. P. K. and Parker, D. J. (2000). Solids motion in bubbling gas fluidized beds, Chemical Engineering Science, 55,5291-5300

Table 1. Physical Properties Of Polymers Used In This Study

\begin{tabular}{lll}
\hline Parameters & Polymer A (white) & Polymer B (black) \\
\hline Mean particle size, $d_{p}(\mu \mathrm{m})$. & 3465 & 3502 \\
Particle density, $\rho_{p}\left(\mathrm{~kg} / \mathrm{m}^{3}\right)$ & 923 & 1105 \\
Bulk density, $\rho_{b a}\left(\mathrm{~kg} / \mathrm{m}^{3}\right)$ & 617 & 745 \\
Geldart classification $(1973)$ & $\mathrm{D}$ & $\mathrm{D}$ \\
Size range, $d_{p}(\mu \mathrm{m})$. & $4750-2360$ & $4750-2360$ \\
\hline
\end{tabular}

Table 2. Experimental series for mixing in a fluidized bed

\begin{tabular}{ll}
\hline Parameters & Range of values \\
\hline$U_{m f}(\mathrm{~m} / \mathrm{sec})$ & 1.35 \\
Operating gas velocity & $U_{m f, 1.15 U_{m f} \text { and } 1.38 U_{m f}}$ \\
Bed depth, $H(\mathrm{~cm})$ & 10,15 and 17 \\
Bed weight, $m(\mathrm{~kg})$ & $1.042,1.563$ and 1.772 \\
$H_{m s c}(\mathrm{~cm})$ & 18.98 \\
Duration, $t(\mathrm{sec})$ & $5,10,12,15,20$ and 30
\end{tabular}


Table 3. Parameters used in the V-mixer.

\begin{tabular}{ll}
\hline Parameter & Range of values \\
\hline Rotation speed (rpm) & 20,40 and 60 \\
Filled up level \% & 40,50 and 70 \\
Duration, t (min) & 5,10 and 20 \\
\hline
\end{tabular}

Table 4. Optimum mixing time at best parameters condition and power consumption for each mixer

\begin{tabular}{llllll}
\hline $\begin{array}{l}\text { Type of } \\
\text { mixer }\end{array}$ & $\begin{array}{l}\text { Mass } \\
(\mathrm{kg})\end{array}$ & Velocity & $\begin{array}{l}\text { Mixing } \\
\text { index }(-)\end{array}$ & $\begin{array}{l}\text { Optimum } \\
\text { time }(\mathrm{sec})\end{array}$ & $\begin{array}{l}\text { Power consumption } \\
(\mathrm{J} / \mathrm{kg})\end{array}$ \\
\hline $\begin{array}{l}\text { Fluidized } \\
\text { bed }\end{array}$ & $\begin{array}{l}17 \mathrm{~cm} \text { bed } \\
\text { depth=1.772 }\end{array}$ & $\begin{array}{l}\text { Gas velocity } \\
=1.38 U_{m f}\end{array}$ & 0.99 & 7 & 0.015 \\
V-mixer & $\begin{array}{l}40 \% \text { filled up } \\
\text { Rotation speed }\end{array}$ & $\begin{array}{l}0.99 \\
\text { 40 rpm, }\end{array}$ & & 240 & 9 \\
& & & & \\
\hline
\end{tabular}

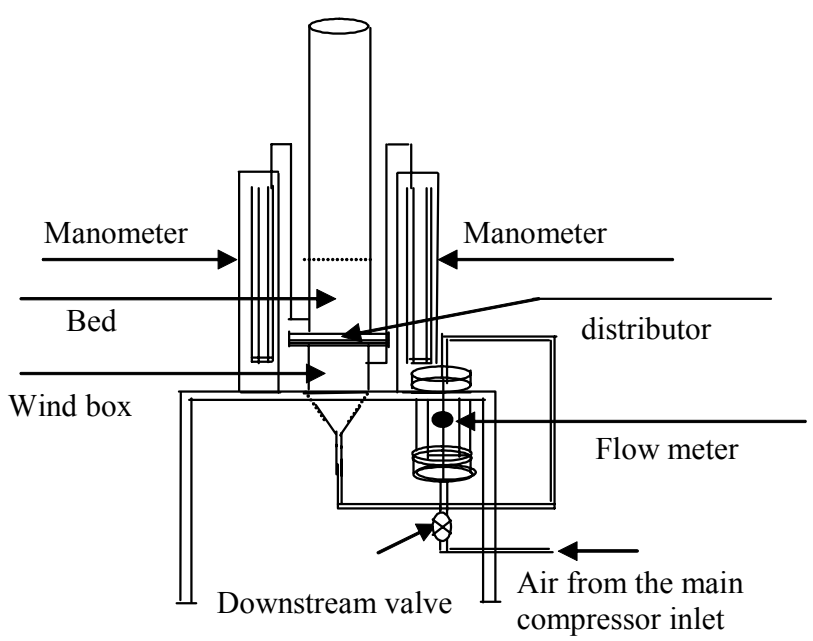

Figure 1. Experimental set-up of the mixing fluidized bed

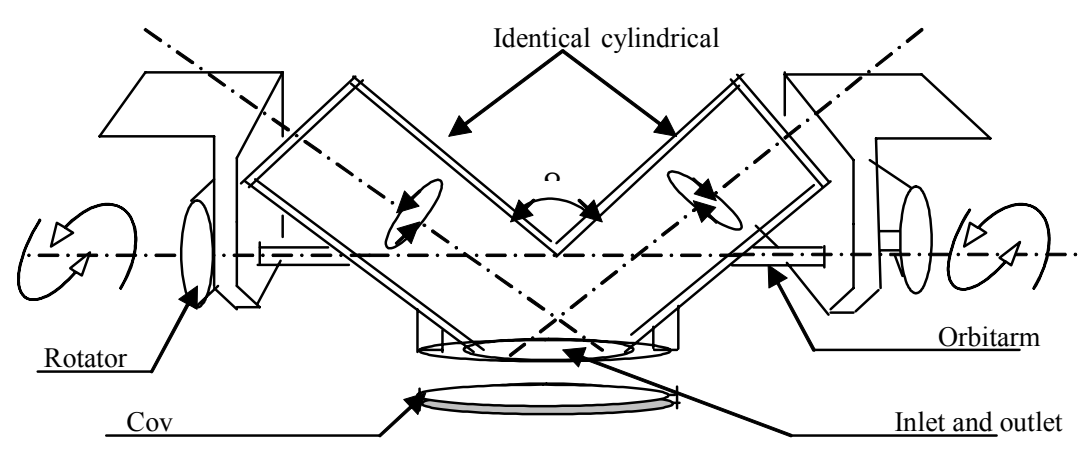

Figure 2. The schematic diagram of the V-mixer 

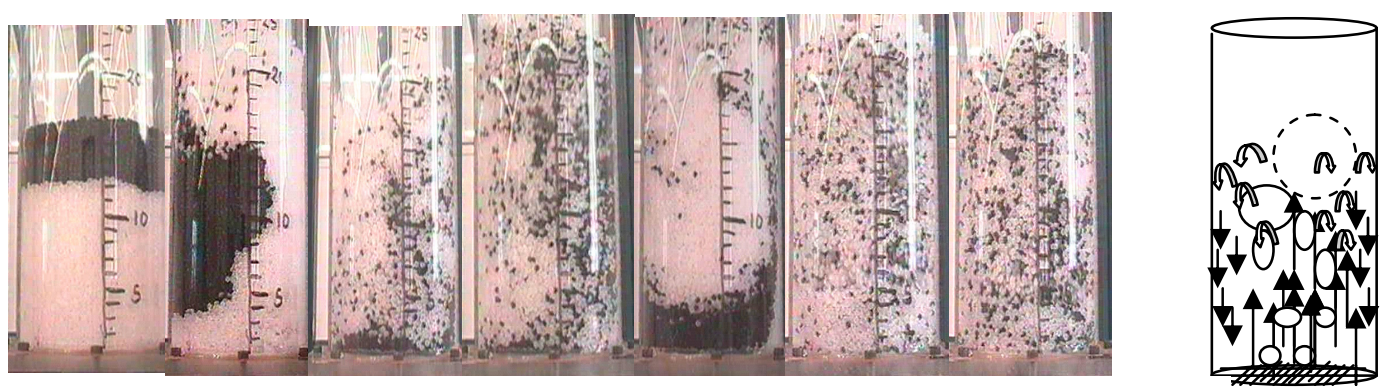

$t=0 \mathrm{~s} \quad t=1 \mathrm{~s} \quad t=3 \mathrm{~s} \quad t=5 \quad t=6 \mathrm{~s} \quad t=9 \mathrm{~s} \quad t=12 \mathrm{~s}$

Figure 3. An illustration of the process of mixing (bed depth $=17 \mathrm{~cm}$, superficial gas velocity $\left.=1.38 U_{m f}\right)$

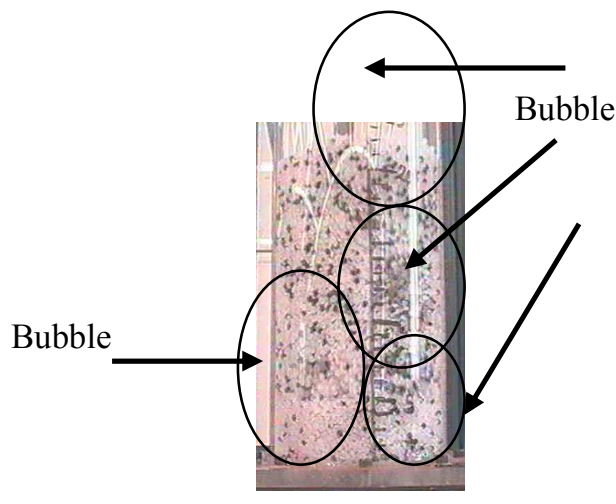

(a)

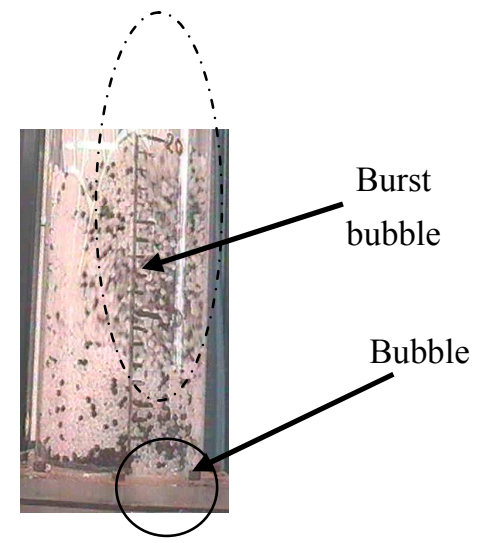

(b)

Figure 4. An illustration the bubbles behaviour of polymers mixing

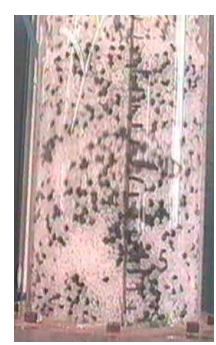

(a)

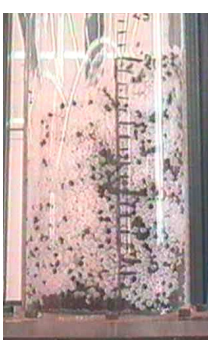

(b)

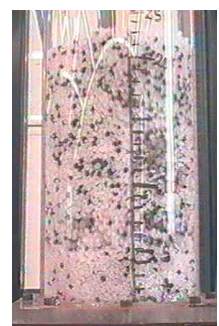

(c)

$\mathrm{H}=15 \mathrm{~cm}, \mathrm{t}=5 \mathrm{~s}$

$\mathrm{H}=17 \mathrm{~cm}, \mathrm{t}=5 \mathrm{~s}$

$\mathrm{H}=17 \mathrm{~cm}, \mathrm{t}=9 \mathrm{~s}$

Figure 5. Influence of bed depth on the degree of homogeneity of mixtures with time

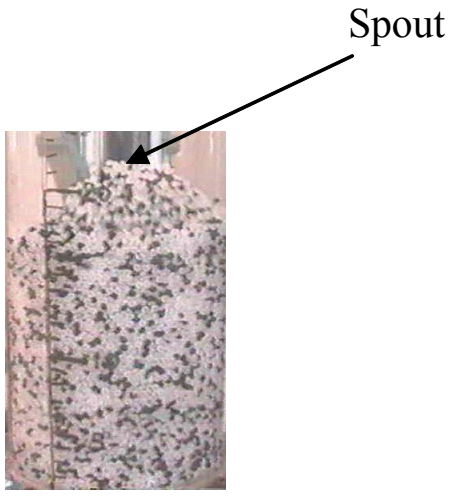

Figure 6. Photograph shows the spout of homogenous mixture at bed depth of $17 \mathrm{~cm}$ and gas velocity of $1.38 U_{m f}$ 

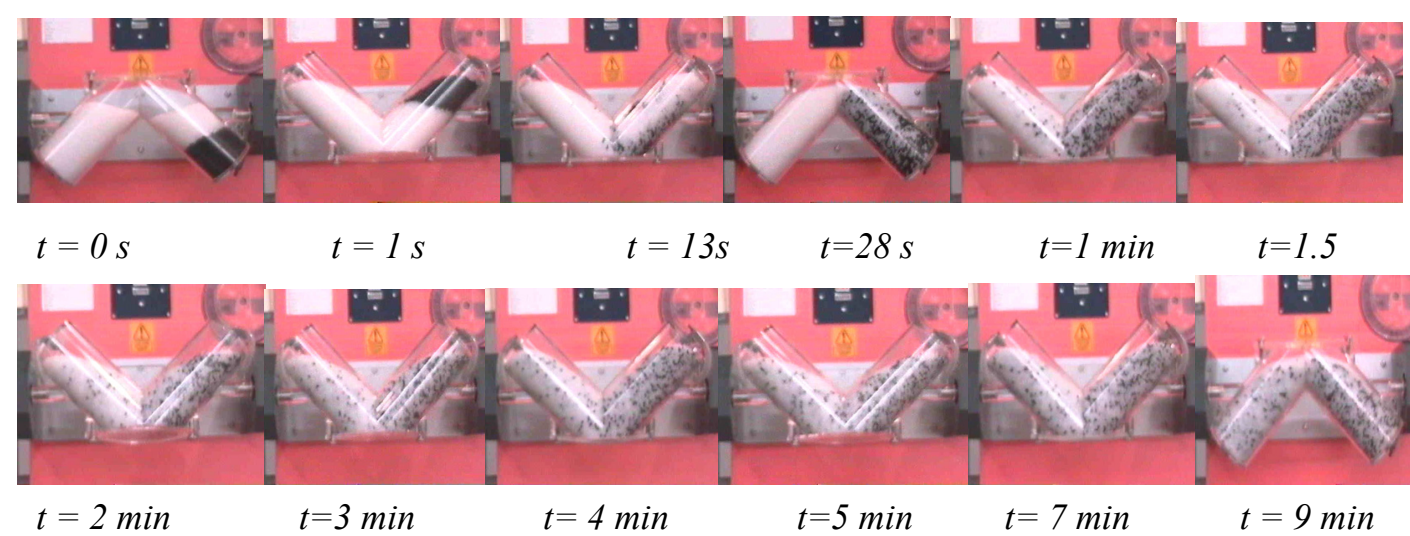

Figure 7. Photographs illustration the mechanism of mixing formation of polymers, also it shows surface composition at different time, $(70 \%, 60 \mathrm{rpm})$

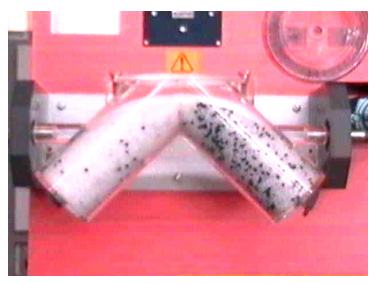

$20 \mathrm{rpm}$

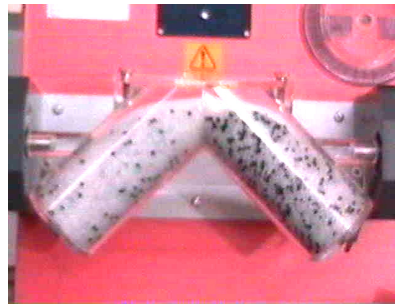

$40 \mathrm{rpm}$

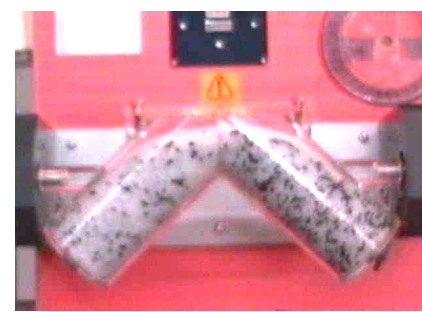

$60 \mathrm{rpm}$

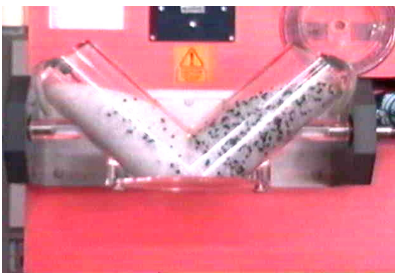

$20 \mathrm{rpm}$

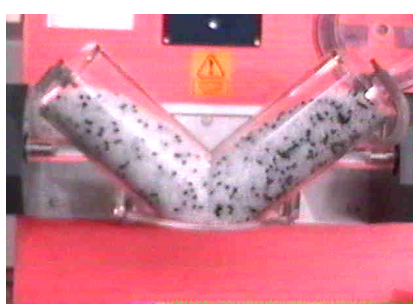

$40 \mathrm{rpm}$

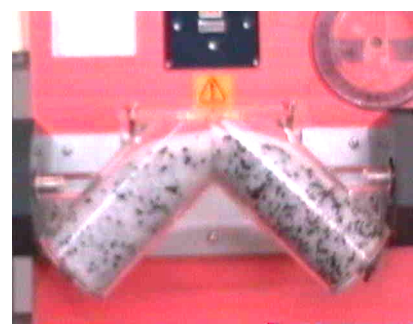

$60 \mathrm{rpm}$

Figure 8. Effect of rotational speeds on mixing index at $70 \%$ filled up and $t=10 \mathrm{~min}$ 


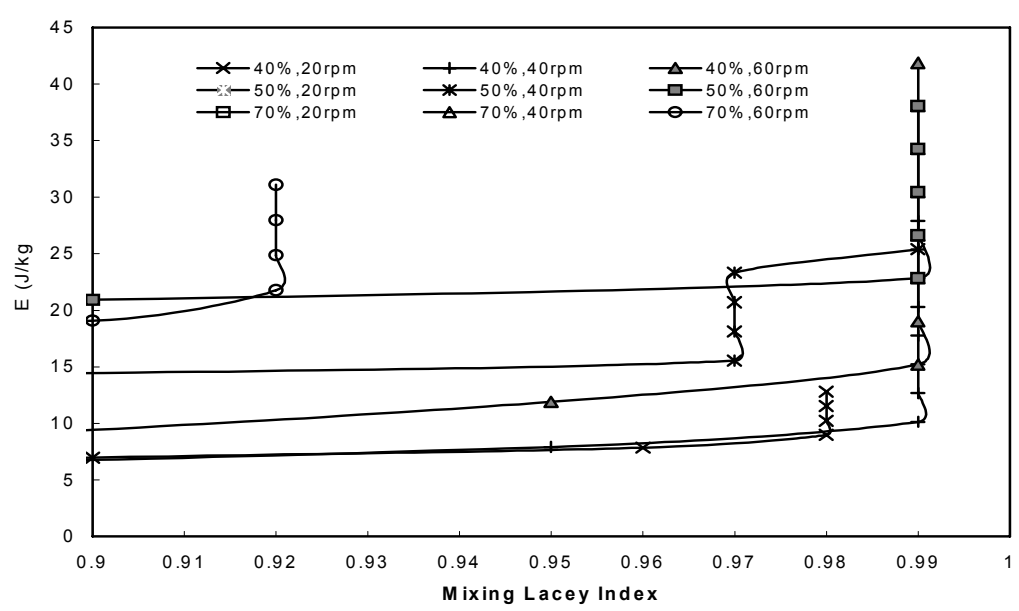

Figure 9. Specific energy consumption, $E(\mathrm{~J} / \mathrm{kg})$.vs. Lacey mixing index, $M(-)$ for mixing in $\mathrm{V}$-mixer with mixing index, $M$ from 0.9 to 1

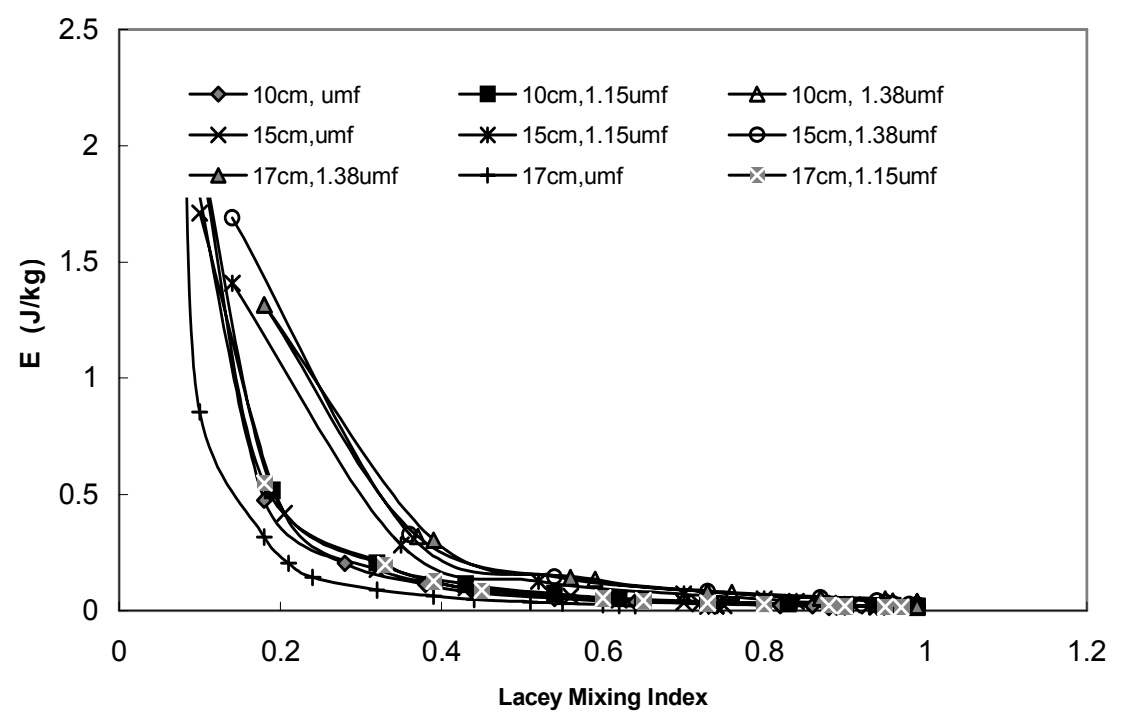

Figure 10. Specific energy consumption, E (J/kg) .vs. Lacey mixing index, M (-) for Fluidized bed; For energy consumption from 0 to $2.5 \mathrm{~J} / \mathrm{kg}$

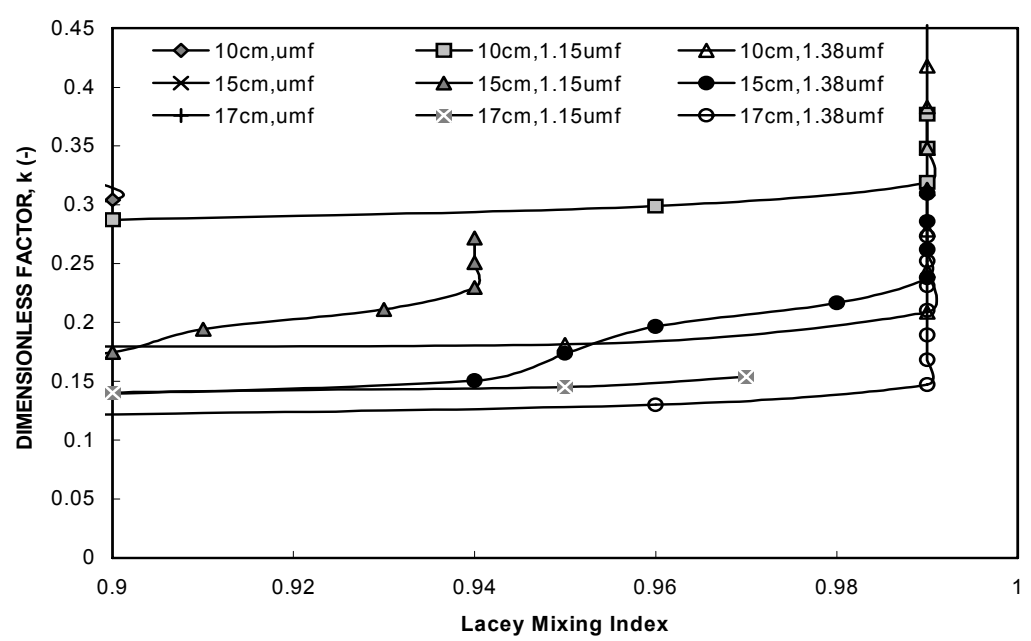

Figure 11. Dimensionless mixing factor, $K$.vs. Lacey mixing index, $M(-)$ for Fluidized bed;

(a) For mixing index, $M$ from 0 to 1, (b) For mixing index, $M$ from 0.9 to 1 